\title{
Numerical Simulation of Pore Water Distribution Under Electric Field in Unsaturated Soils
}

\section{Yimin Liu ( $\nabla$ yiminliu@zju.edu.cn )}

Shenzhen University

Chuntai Xu

Zhejiang University

Xiada Zhu

Zhejiang University

\section{Research Article}

Keywords: Unsaturated soils, water distribution, governing equation, hydraulic permeability coefficient

Posted Date: December 20th, 2021

DOI: https://doi.org/10.21203/rs.3.rs-1155192/v1

License: (c) (i) This work is licensed under a Creative Commons Attribution 4.0 International License. Read Full License

Version of Record: A version of this preprint was published at International Journal of Electrochemical Science on May 1st, 2022. See the published version at https://doi.org/10.20964/2022.05.59. 


\title{
Numerical simulation of pore water distribution under electric field in unsaturated soils
}

\author{
Yimin Liu ${ }^{* 1,3}$, Chuntai $\mathrm{Xu}^{2}$, Xiada $\mathrm{Zhu}^{2}$, \\ 1. College of Civil and Transportation Engineering, Shenzhen University, Shenzhen, China \\ 2. Ningbo Institute of Technology, Zhejiang University, Ningbo, China \\ 3. Shenzhen Talents Housing Group Co. Ltd, Shenzhen, China
}

\begin{abstract}
A numerical model predicting the moisture distribution under external electric field in unsaturated soils is established. Key parameters including matric potential, hydraulic and electrical permeability coefficient and electric conductivity are discussed. The simulation results are in good agreement with the measured data from literaturea, which verify exactness and suitability of the model. In general, the moisture contents decrease with time under the action of external electric force and matrix suction. A slight increase in moisture contert was observed in the anodic area at the beginning of the treatment. The electro-osmosis treatment effect can be enhanced by improving the voltage gradient or weaken the voltage loss at electrode. The limit value of electroosmosis treatment in moisture content is observed and the method can only be applied on the soil with moisture content higher than the limit value.
\end{abstract}

Keywords: Unsaturated soils; water distribution; governing equation; hydraulic permeability coefficient 


\section{Introduction}

Pore water flow generated during the electro-osmosis(EO) process is irrelevant to the hydraulic conductivity. Therefore, electro-osmosis treatment on fine grained soil with low permeability has been applied on more and more practical geotechnical projects $^{[1,2]}$ including disposals of industrial sludge, marine clay reinforcement and stabilization, land reclamation, and foundation excavation, etc. In order to fully understand the EO process and provide guidelines to the project practice, critical parameters ${ }^{[3,4]}$ affecting the effect such as electrode material, applied voltage gradient, soil conductivity and additional chemical treatment were studied through indoor experiments and abundant theoretical models were investigated. One dimensional theory was first derived by Esrig ${ }^{[5]}$ which is on the assumption that water flow generated by the hydraulic force and electric force can be linearly superimposed. Wan and Mitchell ${ }^{[6]}$ developed an analytical model which take account of coupled effects of surcharge and EO.

Most of the existing electroosmotic theories are focused on the consolidation of saturated soil, which failed to care about the unsaturated soil. On one hand, besides that unsaturated soils are less common in coastal areas where electroosmosis is often used to treat dredged soft soils, the electroosmotic consolidation theory of unsaturated soil involves the interaction among solid, liquid and gas phases. The governing equations are usually highly nonlinear and difficult to get the analytical solution. On the other hand, the volume of $\mathrm{H}_{2}$ and $\mathrm{O}_{2}$ generated by electrolysis reaction at the electrode which 
intruded into the soil, leading to a desaturation of soil, are hard to quantified. Researchers used finite element software to simulate the electroosmosis of unsaturated soil ${ }^{[7,8]}$, assuming that only the $\mathrm{O}_{2}$ generated by the anode entered the soil and $\mathrm{H}_{2}$ at the cathode is expelled directly into the atmosphere. The ratio of the gas entering the soil to the total generated oxygen is a constant value $\eta$. The simulation results show that the value of $\eta$ has a strong effect on the development of pore pressure. For instance, the final pore pressure in anode soil reach to $-200 \mathrm{kPa}$ when $\eta=0.1$ while it turns to be $-500 \mathrm{kPa}$ when $\eta=0.4$.

The behavior of unsaturated soil under electric field is quite different from that of saturated soil. In this paper, a numerical model for unsaturated soils water distribution under electroosmosis process is established. The simulation results are compared with the existing data in literatures.

\section{Numerical model}

\subsection{Governing equation}

The model is one-dimensional, thus the directions of current, flow and settlement are vertical and parallel to each other, as shown in Fig. 1. The assumption for the model are listed below. 


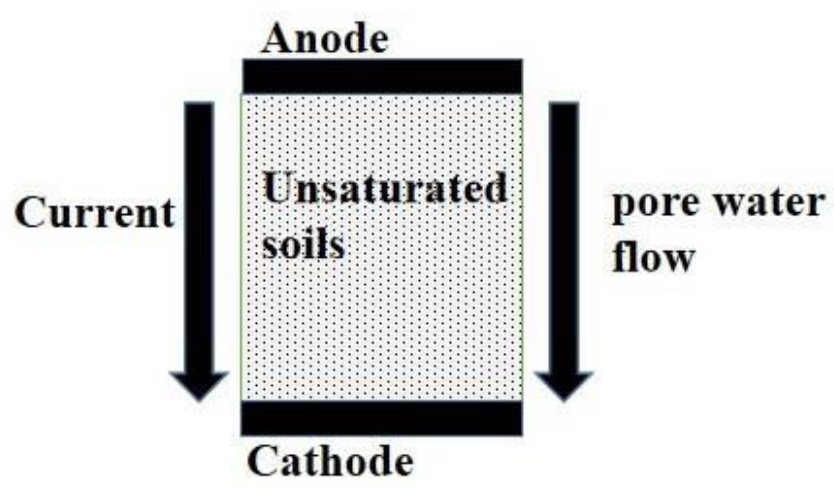

Fig. 1. Schematic diagram of one-dimensional electroosmosis of unsaturated soil

1) the migration of pore water follows Darcy's law.

2) gases generated by hydrolysis reactions all enter the atmosphere and the pores in soil are connected with the atmosphere.

3) the hydraulic permeability, electric permeability coefficient and electrical conductivity are functions of moisture content.

4) soil shape does not change with the change of water content.

5) other assumptions are the same as the Esrig one dimensional electroosmotic consolidation theory.

The seepage of unsaturated soil usually takes the total potential energy of pore water as the variable. The flow rate caused by the gravity potential and matrix potential can be written as:

$$
\begin{aligned}
& \vec{q}_{h}=-k_{h}(\theta)[\nabla \psi \\
& \psi=\psi_{m}(\theta)+z
\end{aligned}
$$


In the equations above, $k_{h}(\theta)(\mathrm{m} / \mathrm{s})$ is the hydraulic permeability coefficient of unsaturated soil. $\Psi(\mathrm{m})$ is the soil water potential, $\Psi_{m}(\theta)(\mathrm{m})$ stands for the matrix potential while $\mathrm{z}(\mathrm{m})$ for gravity potential. $\theta$ is the volumetric moisture content of the soil

The flow rate under electric field can be described as follow:

$$
\vec{q}_{e}=-k_{e}(\theta)[\nabla \phi
$$

where $k_{\mathrm{e}}(\theta)$ is the electric permeability coefficient of unsaturated soil, $\phi$ is the electric potential. According to Esrig's theory, seepage caused by electric field and gravity potential can be superimposed linearly. Hence the total flow rate $q$ is:

$$
\vec{q}=\vec{q}_{e}+\vec{q}_{h}=-k_{e}(\theta) \square \nabla \phi-k_{h}(\theta) \nabla \psi
$$

In this situation, neglecting the mass of water electrolysised and assuming pore water does not move soil particles when it migrates, the mass continuity equation for the liquid phase can be written as:

$$
\frac{\partial \theta}{\partial t}+\nabla\left[\vec{q}=\frac{\partial \theta}{\partial t}+\nabla\left[-k_{e}(\theta)\left[\nabla \phi-k_{h}(\theta) \nabla \psi\right]=0\right.\right.
$$

For an isolated system consisting of soil and electric circuit, the total charge is conserved. Ohm's law and the principle of charge conservation give us equation:

$$
C_{p} \frac{\partial \phi}{\partial t}+\nabla\left[-\sigma_{e}(\theta) \nabla \phi\right]=0
$$

Where $C_{\mathrm{p}}\left(\mathrm{F} / \mathrm{m}^{3}\right)$ is the unit capacitance while $\sigma_{\mathrm{e}}(\theta)(\mathrm{s} / \mathrm{m})$ is the conductivity of unsaturated soil. Equations (5) and (6) are the governing equations for the coupled 
electric-seepage field of unsaturated soil.

\subsection{Soil characteristic parameters}

\section{1)The matric potential $\Psi m(\theta)$}

The matrix potential of soil can be described by soil water characteristic curve and typical curve are illustrated in Fig. 2. The infection point $h_{d}$ is the critical value of air-entry suction, related to the particle size, pore size and shape of soil particles, etc.

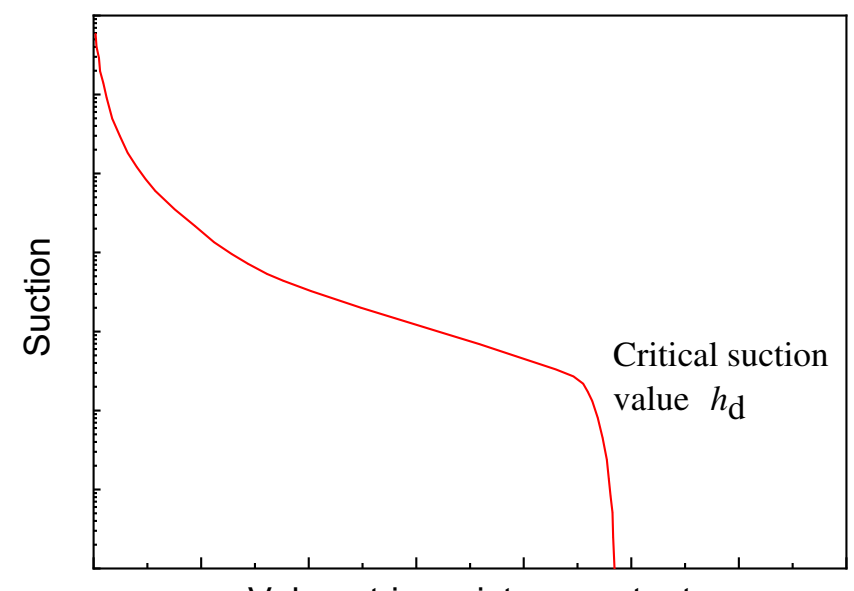

Volumetric moisture content

Fig. 2. Typical soil water characteristic curve

In order to describe the mathematical form of the curve, standardized volumetric moisture content $\Theta$ and effective saturation $S_{e}$ are adopted, as below:

$$
\Theta=\frac{\theta-\theta_{r}}{\theta_{s}-\theta_{r}}
$$




$$
S_{e}=\frac{S-S_{r}}{1-S_{r}}
$$

$\theta_{r}$ and $S_{r}$ are the residual volume moisture content and residual saturation, corresponding to only hydroscopic water existing in soils. $\theta_{s}$ is the saturated volume moisture content. It is notable that these two indexes are numerically equal. This paper adopts an empirical model established by Van Genuchten ${ }^{[9]}$ to characterize the curve. The expression is as follow:

$$
\Theta=S_{e}=\left[\frac{1}{1+\left(a \psi_{m}\right)^{n}}\right]^{m}
$$

where $a$--- fitting parameter related to air intrusion,

$m$--- fitting parameter of the curve, $m=1-1 / n$ or $m=1-1 / 2 n$

$n$--- parameter related to the pore distribution of soil

\section{2) Hydraulic permeability coefficient of unsaturated soil}

Calculating the permeability coefficient of unsaturated soil from conventional constitutive equation such as soil-water characteristic curve or predicting from experimental data is of great concern to scholars. Mualem ${ }^{[10]}$ classified these methods into three categories: empirical, macroscopic and statistical model. In this paper, a statistical model proposed by Van Genuchten is employed. The model comprehensively considerd the soil-water characteristic curve and obtained a closed smooth equation: 


$$
k_{h, r e l}=\left[\frac{1-\left(\alpha \psi_{m}\right)^{n-1}\left[1+\left(\alpha \psi_{m}\right)^{n}\right]^{-m}}{\left[1+\left(\alpha \psi_{m}\right)^{n}\right]^{m / 2}}\right]
$$

Submitting the standardized volume moisture content into equation(10), we get:

$$
\left\{\begin{array}{l}
k_{h, r e l}=\Theta^{1 / 2}\left[1-\left(1-\Theta^{1 / m}\right)^{m}\right]^{2} \\
k_{h, r e l}=k_{h} / k_{h, \text { sat }}
\end{array}\right.
$$

Where $k_{h, r e l^{--}}$relative hydraulic permeability coefficient

$k_{h, s a t^{--}}$hydraulic permeability coefficient when saturated

\section{3) Electrical permeability coefficient of unsaturated soil}

The water content decreases with the development of electroosmosis, leading to a desaturation among the soil. The decrease of saturation will lead to the increase of resistivity and the decrease of permeability coefficient. For saturated soil, Helmholtz-Smoluchowski(H-S) theory has been widely accepted in the current research on the coefficient of electrical permeability. This model is established on the basis that the electric field forces applied on the ions balance the viscous forces due to uneven water velocity in a stable flow, which failed to consider the effect of matrix suction when it comes to unsaturated condition. Studies show that in fine grained soils, the matric suction at low saturation has a greater effect than other water heads ${ }^{[11]}$.A modified model ${ }^{[12]}$ which take degree of saturation into account is needed in this paper. The relative electroosmotic permeability can be expressed using power function: 


$$
\left\{\begin{array}{l}
k_{e, r e l}=a(S)^{b} \\
k_{e, r e l}=k_{e} / k_{e, s a t}
\end{array}\right.
$$

Submitting the standardized volume moisture content into equation(11), we get:

$$
\left\{\begin{array}{l}
k_{e, r e l}=a\left[S_{r}+\Theta\left(1-S_{r}\right)\right]^{b} \\
k_{e, r e l}=k_{e} / k_{e, s a t}
\end{array}\right.
$$

Where $k_{e, e^{---}}$relative electroosmotic permeability coefficient

$k_{e, s a t^{--}}$electroosmotic permeability coefficient when saturated

$a, b$--- fitting parameters

\section{4) Soil conductivity}

Soil conductivity is influenced by moisture content, fluid salinity, temperature and many other factors. Under the condition of low water content (10\% 60\%) and constant porosity, the conductivity shows approximate linear increase with water content ${ }^{[13]}$. According to the assumption above, the geometric deformation is neglected and the moisture content for unsaturated soil is relatively low. Hence, the conductivity of soil is:

$$
\sigma_{e}(\theta)=A+B \theta
$$

Where, $A=-0.027, B=32$. 


\section{Results and Discussion}

\subsection{Testing parameters}

In order to validate the rationality and validity of the model, an experiment ${ }^{[14,15]}$ was compared with the results of the model. The soil in the literature have a 20.3 29.8\% moisture content, $38.69 \%$ liquid limit and $22.16 \%$ plastic limit. The soil-water characteristic curve fitting parameters are listed in Table. 1 below.

Table. 1 Soil-water characteristic curve fitting parameters

\begin{tabular}{|c|c|c|c|c|c|}
\hline$\theta_{s}(\%)$ & $\theta_{\mathrm{r}}(\%)$ & $S_{\mathrm{r}}$ & $\alpha\left(\mathrm{kPa}^{-1}\right)$ & $\begin{array}{c}\text { Fitting } \\
\text { parameter } \\
m\end{array}$ & $\begin{array}{c}\text { Fitting } \\
\text { parameter } \\
n\end{array}$ \\
\hline 43.96 & 29.24 & 0.665 & 0.002 & 1.79 & 1.86 \\
\hline
\end{tabular}

The standardized volume moisture content is:

$$
\Theta=\frac{S-S_{r}}{1-S_{r}}=\left[\frac{1}{1+\left(\alpha \psi_{m}\right)^{n}}\right]^{m}=\frac{\theta-29.24}{43.96-29.24}=\left[\frac{1}{1+\left(0.002 \psi_{m}\right)^{1.86}}\right]^{1.79}
$$

The permeability coefficient of saturated soil was measured in laboratory, which is $k_{\mathrm{h}, \mathrm{sat}}=2.31 \times 10^{-9} \mathrm{~m} / \mathrm{s}$, hydraulic permeability coefficient for unsaturated soil is:

$$
\begin{aligned}
& k_{h}=k_{h, s a t} \Theta^{1 / 2}\left[1-\left(1-\Theta^{1 / m}\right)^{m}\right]^{2} \\
& =2.31 \times 10^{-9} \times\left(\frac{\theta-29.24}{43.96-29.24}\right)^{0.5} \times\left\{1-\left[1-\left(\frac{\theta-29.24}{43.96-29.24}\right)^{\frac{1}{1.79}}\right]^{1.79}\right\}^{2}
\end{aligned}
$$

The typical electric permeability coefficient ${ }^{[16]}$ of saturated soil is $2 \times 10^{-9} \mathrm{~m}^{2} / \mathrm{s} \cdot \mathrm{V}$ 
and the fitting parameters $a=1, b=3$. Therefore, the electrical permeability coefficient of unsaturated soil is:

$$
k_{e}=2.0 \times 10^{-9} \times\left[0.2924+\frac{\theta-29.24}{43.96-29.24}(1-0.2924)\right]^{3}
$$

\subsection{Boundary condition}

The experiment diagram is shown in Fig. 3. A $300 \mathrm{~mm}$ height cylindrical soil sample, encompassed by a ceramic column with measuring holes, are sandwiched by anode above and cathode beneath. The applied voltage is $30 \mathrm{~V}$ and the gradient is $1 \mathrm{~V} / \mathrm{cm}$. The $\mathrm{z}$-axis takes the bottom of the soil sample as the origin and the vertical upward is positive. The experiment starts after the capillary water reaches a stable state.

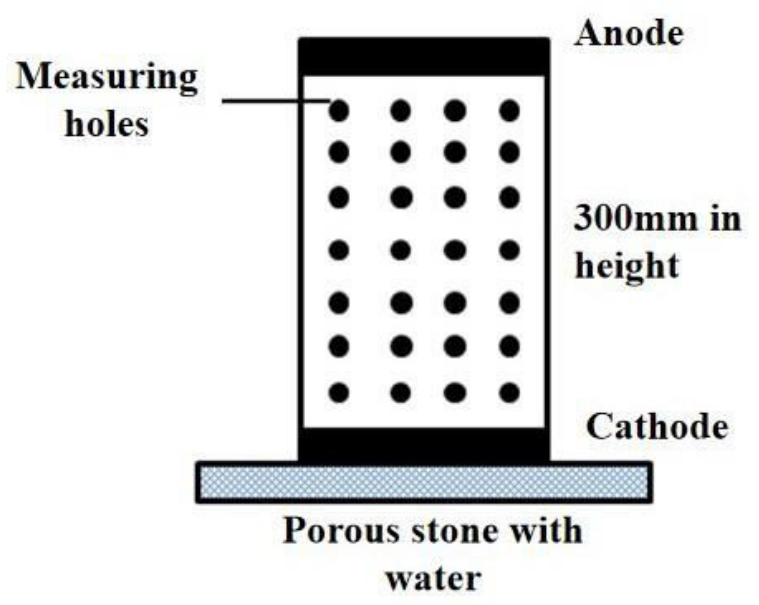

Fig. 3. Testing diagram

Initial water distribution and its nonlinear fitting equation are given and by the 
literature above:

$$
\left.\theta\right|_{t=0}=44.56-14.58 e^{-0.5 \times\left(\frac{z-0.2809}{0.0943}\right)^{2}}
$$

The boundary condition are listed as follow:

$$
\left\{\begin{array}{l}
\left.\frac{\partial \theta}{\partial z}\right|_{z=0}=k_{h, s a t}=2.31 \times 10^{-9} \\
\left.\frac{\partial \theta}{\partial z}\right|_{z=0.3}=0 \\
\phi_{k=0}=0 \\
\phi_{k=0.3}=30
\end{array}\right.
$$

\subsection{Results and discussion}

The partial differential equations are solved using Matlab. The measured data in the experiment and the calculation results of the above equations are drawn below. Fig. 4 illustrates the volume moisture contents at different height of soil at different time. Data from four separated location, $\mathrm{z}=50 \mathrm{~mm}, 130 \mathrm{~mm}, 210 \mathrm{~mm}, 250 \mathrm{~mm}$ are investigated. 


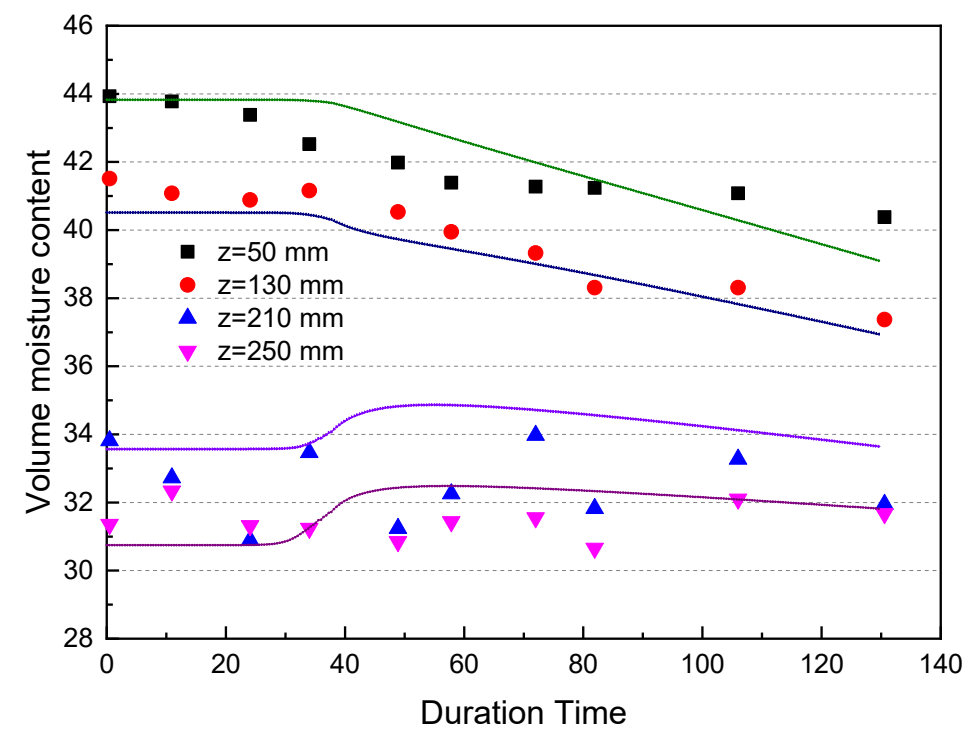

Fig. 4. Water distribution vs. Time

The simulated value coincide well with the experimental results. At $\mathrm{z}=50 \mathrm{~mm}$ and $130 \mathrm{~mm}$, the volume moisture content decreases with time. At $\mathrm{z}=210 \mathrm{~mm}$ and $250 \mathrm{~mm}$, the water content decline gradually after a slight increase.

Pore water migration are driven by both electric force and matric suction, the soil matrix suction causes upward migration while electric force leads to downward. When the moisture content is high, i.e. $\mathrm{z}=50 \mathrm{~mm}$ and $130 \mathrm{~mm}$, the matrix suction is smaller than electric force, which resulting in moisture decreases with time. On the contrary, matrix suction dominate the migration trend when the water content is relatively low at $\mathrm{z}=210 \mathrm{~mm}$ and $250 \mathrm{~mm}$ at the beginning of the test. After these two forces reach equilibrium at about $35 \mathrm{~h}$, pore water reverses its migration direction. The above results indicate that the effect of electroosmosis is more suitable for unsaturated soil with high water content rather than low water content, which is similar to that of saturated soil.

After a long enough treatment time, it is found that the final value all over the soil 
tend to remain stable, in this case, about $29 \sim 30 \%$ at $1.7 \times 10^{5}$ h.(See Fig. 5) Soil with a high initial moisture content decreases at a faster rate, while slower with relatively low initial moisture content. Under ideal conditions, the water will move to cathode where drainage is allowed, under the action of matrix suction and electric force when an external electric field is applied. When the water content drops to a certain critical value, the effect of matrix potential and electric potential on pore water reaches a dynamic balance, manifesting that water content no longer changes over time. This indicates that there exsits a limit in electro-osmosis treatment: if the electroosmosis method is used to treat the soil with water content lower than the critical value, the effect cannot be achieved.

From the above discussion, the critical value can be reduced by increasing the electric field force or decreasing the matric suction. Generally speaking, it is easier to improve the electric field force, for instance, improving the potential gradient ${ }^{[17]}$ or employing electrode materials with low potential loss ${ }^{[18]}$, etc.

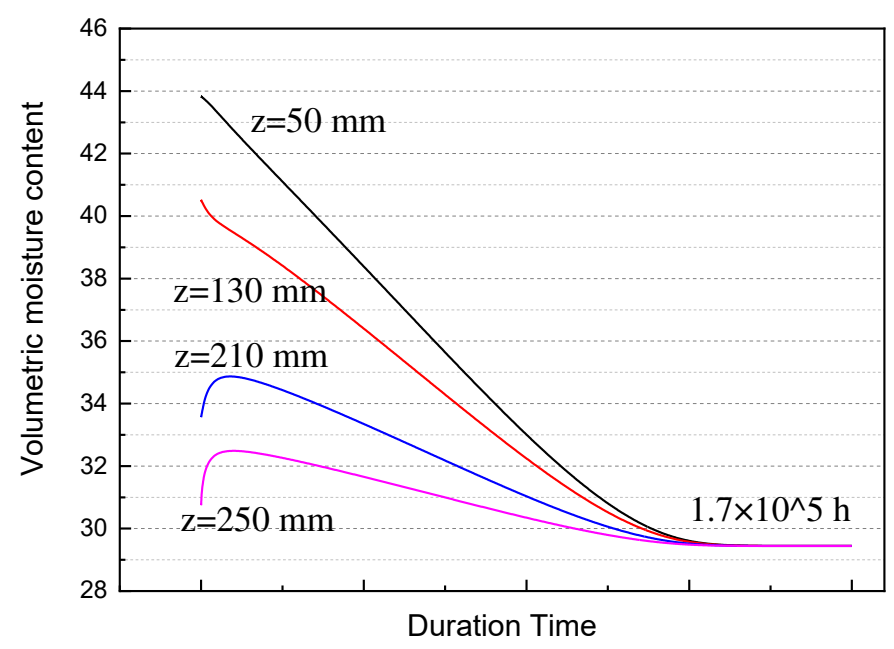


Fig. 5 Water distribution vs. Time

\section{Conclusion}

In this paper, the governing equation for pore water distribution under electric field in unsaturated soils are driven through mass continuity equation and principle of charge conservation. From the statements above, we can conclude:

1) the simulation results is highly consistent with the data in the literature, which validates the applicability of the one-dimensional water migration model.

2) numerical results show the moisture contents decrease with time under the action of external electric force and matrix suction. A slight increase in moisture contert was observed in the anodic area at early stage due to the matrix potential. The electro-osmosis treatment method can only be applied on the soil with moisture content higher than the critical value.

\section{Acknowledgement}

The authors greatly acknowledge for the financial supports from the Natural Science Foundation in Zhejiang Province, China (LQ19E080009), and the Application Research of Public Welfare Technology in Ningbo, China (No. 2019C50016). 


\section{References}

1. Lockhart, NC. Electroosmotic dewatering of clays, I. Influence of voltage [J]Colloids and Surfaces 1983, 6(3):229-238.

2. Mitchell, J.K. Conduction phenomena: from theory to geotechnical practice [J]. Geotechnique 1991, 41(3):299-340.

3. Xin-yu X., Ling-wei Z., Kang-he X., et. al. Experimental study on electro-osmosis of marine soft soil with varying potential gradient and electrode spacing [J]. China Civil Engineering Journal, 2019,52(1):108-121

4. Ou C Y, Chien S C, Yang C C and Chen C T. Mechanism of soil cementation by electroosmotic chemical treatment [J]. Applied Clay Science. 2015, 104: 135-142

5. Esrig M. I. Pore pressure. Consolidation and electrokinetics [J]. Journal of the SMFD, ASCE. 1968, 94(4):899-922.

6. Wan T.Y., Mitchell J.K. Elctro-osmotic consolidation of soils[J]. Journal of the Geotechnical Engineering Division, 1976, 102(5):473-491.

7. Tamagnini C, Jommi C and Cattaneo F. A model for coupled electro-hydro-mechanical processes in fine grained soils accounting for gas generation and transport [J]. Anais Da Academia Brasileira De Ciências. 2010, 82(1): 169-193.

8. Yuan $\mathrm{J}$ and Michael A H. Influence of gas generation in electro-osmosis consolidation [J]. International Journal for Numerical \& Analytical Methods in Geomechanics, 2016, 40(11): 1570-1593.

9. Van Genuchten M T. A closed form equation for predicting the hydraulic conductivity of unsaturated soils [J]. Soil Science Society of America Journal, 1980, 44:892-898.

10. Mualem Y. Hydraulic conductivity of unsaturated soils: Prediction and formulas [M].Methods of Soil Analysis, Madison, W1: 799-823.

11. Ning L and William J L. Suction stress characteristic curve for unsaturated soils [J]. Journal of 
Geotechnical \& Geoenvironmental Engineering, 2006, 132(2):131-142.

12. Xin-yu X., Yi-min L. and Ling-wei Z. Experimental study on the effect of soil saturation on the electric permeability coefficient during electroosmosis process [J]. Marine Georesources \& Geotechnology, 2019, 37(10): 1188-1195

13. Ying L., Xiao-nan G., Biao G. and Zhi-gang Z. Research on conductivity characteristics of soft clay during electro-osmosis and its conductive mechanism [J]. Chinese Journal of Rock Mechanics and Engineering, 2010, 29(supp2):4027-4032.

14. Hu-yuan Z., Yu-xi G. Shi-bin Z. and Yu-meng S. Experimental study of restraining capillary rise on ancient earthen sites under moisture circumstance using DC electric field [J]. Journal of Lanzhou University: Natural Sciences, 2016, 52(5):571-576.

15. Bing-zhuo Y. Moisture redistribution in the unsaturated soil subjected to DC electric field [D]. Lanzhou University, 2017.

16. Shang J Q. Zeta potential and electroosmotic permeability of clay soils [J]. Canadian Geotechnical Journal. 1997, 34(4): 627-631.

17. Shang J Q, Lo K Y and Huang K M. Effects of voltage gradient and polarity reversal on electro-osmotic consolidation [C]. Proceedings, 2nd International Conference on Soft Soil Engineering, Nanjing, China, 1996, pp. 966-971.

18. Jun-chao Z., Ling-wei Z. and Xin-yu X. Comparative experiments on electro-osmotic treatment effect of polluted soil using EKG and iron electrodes[J]. Journal of Central South University, 2018, 25(12):3052-3061. 